\title{
Framework for Understanding Leader-Organizational Culture Congruence
}

\author{
Dr. Remy Nyukorong \\ Management Partners (GH), Ghana, West Africa \\ nyukorongr@ymail.com
}

\begin{abstract}
The current paper describes the conceptual foundation and practical application of an innovative framework for coaching business leaders. Build on the person-environment fit theory, the leader-organizational culture fit framework produces a set of conclusions regarding leader-organizational culture congruence and result in a number of unique approaches on coaching. The purpose of the conceptual structure is to create and expand the coach's personal insights concerning how the culture of an organization may provide for the leader's development of specific competencies, while potentially limiting the development of other capabilities. The proposed framework also has the ability to better support leader development approaches, in relation to coaching, with the wider development needs of the organization by identifying strategic ways through which the organizational leader can act as a critical agent for positive culture change. Furthermore, the paper discusses three methodological qualifications for the implementation of the proposed model: the application of parallel characteristics, corresponding measures, as well as evaluative assessments of characteristics. Finally, the paper discusses a number of important challenges and limitations towards implementing the proposed model within a coaching intervention.
\end{abstract}

Keywords: context, leader development, leadership coaching, organizational culture

\section{INTRODUCTION}

The extant literature on leadership development is filled with researchers and practitioners explaining the relevance of context and expressing the need for more responsiveness to leader-environment dynamics (Day, 2000). However, there exists scant empirical research (Porter \& McLaughlin, 2006).This paper is of the view that a similar set of circumstances is also valid with regard to the discipline and practice of coaching. Even though scholars as well as professionals of coaching unquestionably have an unlimited grasp of the business environment in which executive leaders operate, the review of the available coaching literature points to the fact that there is a dearth of evidence-based approaches to appreciating and incorporating context issues into the goals, strategy, as well as delivery of coaching.

Above all, the way that professional coaches collect information in relation to the business environment and design their coaching methods is usually subjective, idiosyncratic and vastly unique (Feldman \& Lankau, 2005; Saporito, 1996). This absence of objectivity stands in complete conflict with the superfluity of evidence based practices for evaluating the particular leader engagement in the coaching process (Bono, Purvanova, Towler, \& Peterson, 2009). For instance, an array of psychometric tools is normally applied to judge the leader's competencies, skills and capabilities, values, personality, and attitude (Allworth \& Griffin, 2005; Bourne, 2008). This psychometric data is usually complemented with the use of multiple sources feedback methods that give additional insight on the performance behaviours of the leader as seen by peers, direct reports, and supervisors (Goodstone \& Diamante, 1998; Luthans \& Peterson, 2003; Smither, London, Flautt, Vargas, \& Kucine, 2003). In this paper, the author argues that context-based evaluations have not received comparable reputation in coaching as scholars and practitioners have not entirely explained (a) the value and significance of evaluations of organizational context surrounded by a person-focused involvement, such as coaching, (b) the attributes of organizational background that are critical for the 
leader's effectiveness, in both the short and long terms, as well as, (c) the conceptual models and related approaches required to combine assessment-driven perceptions of the individual and the organizational conditions.

To assist focus on these gaps, the paper introduces the framework for understanding leader vs. organizational culture congruence (FLOCC), as a theoretical model meant to guide coaching according to the types of alignment between the leader's capabilities and parallel characteristics of the organization's culture. By taking into account qualities of the leader and the organizational culture jointly, and determining areas of both congruence and misfit, professional coaching can be custommade to adequately prepare business leaders for their twin role of functioning within the organization. For majority of corporate leaders, this may entail identifying the different ways in which organizations provide specific opportunities and controls on behaviour and personal development, especially for the immediate survival and success of the leader. Independent of these opportunities and limitations, the effectiveness of several corporate leaders is also dependent on their capacity to positively transform the culture of the organizations they lead. Appreciating the leader organizational culture congruence or fit can facilitate the process of identifying the areas of the organizational culture that require a change and the approaches through which the leader will be better proficient or challenged to accelerate the change process. Implemented through coaching, the fundamental goal of the FLOCC is the improvement of both leader as well as cultural capabilities. Since both leader and organizational culture capabilities get better with the passage of time, this may lead to a better fit, but the main objective of the framework is greater individual as well as organizational effectiveness, and not improved leader alignment with the existing culture. This is because, the culture itself may need to change.

The three methodological prerequisites for implementing the conceptual framework in the discipline of coaching are the use of parallel characteristics, corresponding measures, and the evaluative appraisal of leader and organizational culture features (Caplan, 1987; Edwards, 1991; Kristof, 1996). Additionally, the paper outlines several methodological choices as well as the complementing tradeoffs and practical implications. Before introducing the FLOCC and principal methodological issues in much detail, the paper first of all situate the discussion within the systems approach to coaching and describe person-context fit as the theoretical basis for the proposed conceptual framework (Caplan, 1987; Caplan \& Van Harrison, 1993; Kristof, 1996).

\section{LITERATURE REVIEW}

\subsection{The Systems Perspective of Coaching}

Based on the description of the existing requirements of coaching practice, it might be proposed that there are practically as many methodologies as there are professional coaches. This observation is based on the extensive range of professional focus and experiences of coaches, the many and different clients of coaching interventions, the absence of standardized prescriptions or regulation of coaches, as well as the extensive conflicts regarding the specific tools and processes that are very effective in stimulating behavioural change (Bono et al., 2009; Feldman \& Lankau, 2005).

Although the precise practices of professional coaches differ broadly, several essential principles have become apparent which distinguish professional coaching from other interventions initiated by corporate leaders. Kilburg (1996) describes coaching as the series of behavioural practices applied to enhance a leader's personal satisfaction and job performance, and as a result, organizational effectiveness. Professional coaching interventions normally last within a period of two months up to a year (Kauffman \& Coutu, 2009). It requires a well-defined and highly individualized conversation between a consultant coach and the person being coached (Feldman, 2001; Feldman \& Lankau, 2005). Professional coaching is initiated and carried out for a number of reasons, most generally for the training of high-potential business leaders for occupational advancement, and less generally, for corrective reasons with corporate leaders in danger of derailing (Coutu \& Kauffman, 2009). Nevertheless, fundamental to most professional coaching engagements is an emphasis on timely feedback and behavioural adaptation, with the greatest objective of enhancing the leader's professional advancement and effectiveness within the organization (Bono et al., 2009).

Some recommended techniques for the practice of coaching have emerged from several intellectual traditions. Peltier (2001) identifies five approaches: cognitive, psychodynamic, system-oriented, 
behaviourist, and person-centred. Each approach takes a slightly distinctive emphasis, requires various kinds of engagements, and suggests diverse criteria for assessing growth (Feldman \& Lankau, 2005). What distinguishes a systems-focused approach, the point of view that the current paper's proposed framework most directly characterizes, is its emphasis on the leader as surrounded by a complex system of processes and interconnected system of relationships (Peltier, 2001; Orenstein, 2002; Tobias, 1996). By appreciating the interaction between the person and system, professional coaching can be tailor-made in a way that increases the leader's advancement and promotes congruence with organizational requirements (Peterson, 2009; Saporito, 1996).

The systems-focused approach occasionally describes the person as associated with by the environment, specifying the several ways that business environment targets the experience and significance of behaviour by creating various opportunities and boundaries that leaders have to negotiate and agree on. Nevertheless, the system-oriented perspective disregards the other side of the leader-organizational context interaction (Chatman, 1989; Johns, 2006; Mowday \& Sutton, 1993). Social cognition theory perspective of leadership incorporates the array of decisions and actions which leaders take that can explicitly or implicitly form, change, and impact the context leaders operate in (Klimoski, 2012). From a balanced perspective, Klimoski points to the fact that corporate leaders are correspondingly "kings and pawns", required to work and manage within certain boundaries, but nonetheless assigned or charged with the critical role of transforming organizations. Consequently, professional coaching need to be planned to focus on both issues and accelerate a profound understanding of the organizational imperatives (Feldman \& Lankau, 2005; Kilburg, 1996).

Based on this view, the current paper proposes a conceptual framework for understanding critical agentic leadership (leader-to-context) as well as the opportunities and constraints (context-to-leader) dynamics and taking advantage of these understandings within a systems-focused view to professional coaching. In designing a realistically valuable model, it was important to find solutions to three basic questions. First of all, what is the desirable theoretical foundation to support the model? Secondly, which characteristics or attributes of the context and leader need to be studied? and how can the attributes be compared? Finally, what are the vital methodological prerequisites and alternatives for putting into operation the conceptual framework in coaching? This paper presents the proposed FLOCC model as an attempt to address the first two questions, briefly discuss key methodological concerns in answer to the third and last questions, and wraps up with a discussion of important strategic challenges and constraints.

\subsection{Theoretical Foundation of this Research}

The proposed FLOCC model is rooted in the person-environment fit (P-E fit) theory. The P-E fit model postulates how the agreeability that develops between a unique person and the work environment is a critical dynamic in the person's overall performance and happiness (Caplan, 1987). In particular, academic research has found positive outcomes of improving compatibility on a variety of workplace effects, such as organizational commitment, satisfaction, organizational citizenship behaviours, intent to stay, and job performance (Kristof-Brown, Zimmerman, \& Johnson, 2005; Kristof-Brown \& Guay, 2011), even though some facts have also started to surface in favour of more subtle relationships, including regulated and nonlinear outcomes, and great attention has been given to the potential negative aspects of fit, among which are homogeneity and incongruity (De Cooman et al., 2009; Wheeler, Gallagher, Brouer, \& Sabylnski, 2007).

An extensive analyses of the P-E fit literature likewise profile several decision points linked to how fit or congruence is theorized (Edwards \& Shipp, 2007; Kristof, 1996; Kristof \& Guay, 2011). One perspective concentrates on whether the context meets the desires and choices of the individual (needs-supplies), and whether the individual's capabilities meet the contextual imperatives (demandsabilities). A second perspective describes congruence as either supplementary or complementary. That is, when an individual complements what is currently existent in the workplace or increases what is missing in the work setting. A third approach, based more explicitly on the measure of congruence between the individual and context, for instance, whether a person's core values are related or unrelated to an organization's core values (Chatman, 1989).

Congruence can also be identified and categorized within manifold degrees, such as match with the career, company, task, workgroup, or director (Jansen \& Kristof-Brown, 2006). In view of the 


\section{Dr. Remy Nyukorong}

multidimensional character of the construct, it is crucial to indicate which relative degree (s) one is allowing for in any scientific research or practical treatments of similarity (Edwards \& Shipp, 2007). The conceptual model proposed in the current paper concentrates on leader-organizational culture congruence. Congruent with organizational culture is in itself a multi-level construct, as organizational leaders can exhibit different levels of alignment with a national or societal culture, besides the culture of the company in which leaders work (Burns, Kotrba, \& Denison, 2013). Taking into account both the significance of the culture of a company to corporate performance (Sackmann, 2011) as well as the task of business leaders in designing and sustaining organizational culture (Schein, 1985; Hartnell, Ou, \& Kinicki, 2011), the author preferred to concentrate on the leader's match or compatibility with the organizational culture. It is the discernment of this paper that this latitude best fits the planned objective of the proposed conceptual model (FLOCC)as well as the anticipated outcome from the coaching process to improve business leaders and corporations (Kilburg, 1996). In tandem, the author appreciates that congruence at other stages might also be of great significance to study in coaching. It is also important to note that the framework presented in this paper could be related to fit at other levels.

As explained above, the direction of the proposed framework is somewhat related in range to the person- organization fit (P-O fit) model. To paraphrase Kristof (1996), person-organization fit can be described as the alignment between individuals and corporate organizations that happen when the following conditions are intact: (a) as a minimum, one body makes available what the other desires, or (b), both entities share similar basic attributes. The attributes of the formulation of meaning reflect diverse types of congruence and also give room for certain cases of similarity and dissimilarity between the individual and organization. Proceeding from Kristof's formulation, our proposed model details four fundamental types of congruence, according to the existence or non-existence of elements in the person as well as the organization. Thus, for the purpose of identifying the categories in the framework, the author typifies the strong presence of a characteristic as "high" and relative absence of a characteristic as "low."

As follows, similarity can be attributable to the combined presence (high-high) or combined absence (low-low) of a characteristic or element. Alternatively, dissimilarity can be as a result of a characteristic present in the leader (person) which is lacking in the organizational culture (high-low) and with the order reversed (low high). It is significant to state that the four fundamental typographies postulate examples of congruence and hypothetical incongruence (Harrison, 2007). For the aim of coaching executive leaders, this paper argues that both points of view are necessary to take into account. Besides, the positive effects normally connected with congruence, incongruence or misfit has been interrelated to staff renewal rate (De Cooman et al., 2009) or counterproductive work behaviours if it turned out that the case of staff turnover does not arise (Wheeler et al., 2007).

Furthermore, it is also necessary to distinguish our multi-attribute description of congruence from global congruence formulations. A multi-attribute model produces multiple interpretations with reference to just one person and organization employing an array of parallel or corresponding characteristics, which initiate a common denominator and a starting point for purposes of comparison. Consequently, it is likely to resolve how a leader matches well with some attributes, at the same time, lacking congruence on other attributes and then apply this knowledge to direct the choice between coaching strategies and prospective developmental goals.

More generally, congruence academics have adopted a global congruence view, emphasizing on the measure of overall alignment a leader has with the company. For instance, O'Reilly, Chatman, and Caldwell (1991) designed a q-sort measure, identified as the Organizational Culture Profile used for evaluating the fitness between job applicants' desired organizational culture, as well as, the values adopted and promoted by the company (Caldwell \& O'Reilly, 1990; Chatman, 1989). A research study has discovered that the global extent of values equivalence for fresh employees is positively associated with their later work satisfaction and organizational commitment, but negatively associated with staff turnover (Verquer, Beehr, \& Wagner, 2003). Although this perception could be remarkably valuable as a benchmark for binary contracting assessments (Werbel \& Gilliland, 1999). The current paper's conceptual framework (FLOCC) was developed to assist professional coaches' focus on specific characteristics and development actions. 


\subsection{Critical Leader and Organizational Culture Characteristics}

A lot has been written concerning the dynamic interaction of corporate leaders and organizational culture in addition to their binary impact on organizational effectiveness (Bennis \& Nanus, 1985; Hartnell \& Walumbwa, 2011; Trice \& Beyer, 1991). Schein's (1985) influential work in this field expresses the development and direction of organizational culture to be the single most critical task of executive leadership. Many founding leaders inculcate their personal values and philosophies in the organizations they started through the decisions they make, the processes and structures they design as well as through the people they hire. (Schein, 1983). Subsequently, effective leaders strive to constantly shape the culture using their strategic vision along with the phenomena they focus on, celebrate and honour (Hartnell \& Walumbwa, 2011). The perspective of Schein (1983) also acknowledges the rippling effects which culture has on leadership, in a way that leaders become more and more controlled by the organizational culture over time, mostly during the latter part of the organization's life cycle, when core values and philosophies are firmly rooted.

In view of the critical significance of leader and organizational culture changing aspects, there has been a growing appreciation of the value added through the integration of the cultural viewpoint in the practice of professional coaching (Rothaizer \& Hill, 2010; Tobias, 2004). Regardless of the increasing interest, not many models have been developed that include a systematic evaluation of the culture, nor that make allowance for the incorporation of organizational culture and leader information, as well as those that are in existence to concentrate on societal culture instead of organizational culture.

One concrete example of a societal culture perspective is offered by Coultas, Bedwell, Burke, and Salas (2011) known as the DELTA model, comprising of five aspects: “(a) Determining cultural values, (b) Employing typical coaching techniques, (c) Looking and listening for motivational needs and deficiencies, (d) Tailoring coaching techniques to motivational needs and cultural values, and (e) Assessing the effectiveness of the approaches used (p.149)." The conceptual model was designed with the objective of improving the cultural sensitivity of executive coaching interventions throughout the entire business world and across national boundaries. In constructing the DELTA framework, Hofstede's (1980) cultural dimensions of society were applied as a starting point for understanding hypothetical cross-cultural variations in motivation. Another example is offered by Gilbert and Rosinski (2008), who designed an executive coaching project that deals with the cultural influences and capabilities of individual leaders. Gilbert and Rosinski's (2008) cultural orientations framework (COF) aims at increasing leader self-awareness through the regularities or gaps connecting their adopted cultural orientation and their capacity to integrate diverse orientations (Gilbert \&Rosinski, 2008, Rosinski, 2003). Since both COF and DELTA emphasize elements of identity and societal culture, these perspectives may be specifically most appropriate for cross-cultural coaching situations, for instance, training a leader for an international mission or improving a leader's expertise within an organization or in the context of a culturally diverse team.

Contrary to the above approaches, the FLOCC was developed particularly to aid consultant coaches facilitate agentic leadership and leader development in general within the context of organizational culture. In concert with other researchers, this paper defines organizational culture as the beliefs, values, norms, assumptions, and practices that are espoused by all organizational members and which promote shared understanding and direct work practices and behaviour at different stages of awareness (Denison, 1996; Schein, 1985). Nevertheless, the author also acknowledges the fact that the definition offered in the current paper does not go far enough to clarify the performance significance within the cultural context of the organization. A concern for and curiosity in culture within the discipline of organizational behaviour was driven in advance by several popular textbooks associating organizational culture as a critical ingredient for attaining a high performance organization (Deal \& Kennedy, 1982; Kotter \& Heskett, 1992; Peters \& Waterman, 1982). Following that several empirical works have confirmed the nature and presence of the organizational culture performance relationship, fresh literature reviews on this topic draw attention to the increasing evidence of the explicit consequences that culture has on organizational effectiveness (Coultas et al., 2011; Hartnell, Ou, \&Kinicki, 2011; Sackmann, 2011). Therefore, consistent with Chatman and Cha's (2003) explanation, the current study also regard organizational culture as the array of values, philosophies, norms, and practices that animate and direct performance behaviours inside an organization. 
Consequently, leader-organizational culture congruence denotes the alignment of the corporate leader with the, values, philosophies, norms, and work behaviors that characterize the corporation (Burns et al., 2013). Not long ago, Burns et al. (2013) indicated the paucity of empirical studies so far assessing the influences of leader- organizational culture congruence. They suggest that this the leaderorganizational culture congruence is crucial to the effectiveness of every organization and reveal through a preliminary research that congruence and incongruence can bring about enhanced evaluations of leader success, thus emphasizing the relevance of allowing for both kinds of congruency in future research. These scholars also recognize that, although there has been some progress made in the direction towards ascertaining which characteristics are most critical about a leader's compatibility with societal culture (Yukl, Fu, \& McDonald, 2003), still more systematic investigation is required to design the model and multi-element structures that relate to leaderorganizational culture congruence at the level of the organization.

Based on the conclusions of Burns et al. (2013), the conceptual framework illustrated in this paper can be implemented in a more flexible way to diverse array of leader and organizational culture characteristics. Nevertheless, for reason of presenting the conceptual framework in broader contexts, the paper discusses characteristics in the subsequent paragraphs that concentrate on types of the leader's effectiveness actions, skills and leadership styles which account for effectiveness of a leader in the organization. For instance, teamwork can be described as a corresponding characteristic concerning the leader's competences in creating and developing effective teams as well as the equivalent cultural values and norms that facilitate or hinder teamwork within the organization.

As discussed above, the suggested framework conceptualizes the leader-organizational culture congruence applying the dual assessment of "highs" and "lows" or the degree to which characteristics exist against non-existent. The conceptual framework is subject to assessing leaders and organizational culture by means of either descriptive or prescriptive measurement instruments. Prescriptive instruments try to extrapolate meaning from the evaluation outcomes by developing a measurement technique to explain how scores are connected to specific outcomes of interest, for example, organization or leader effectiveness. In contrast, descriptive instruments assess characteristics without trying to assign meaning or significance to the measurement outcomes. (Ashkanasy, Broadfoot, \& Falkus, 2000). Even though both measurement techniques could be employed, the analysis and interpretation of the framework entails evaluative decisions concerning whether certain characteristics need further development. In the next section that follows, the paper describes these extrapolations and the consequent implications for executive coaching.

\section{Proposed Framework on Leader and Organizational Culture Alignment}

The FLOCC describes leader-organizational culture congruence in relation to the four fundamentalformsdisplayedinFigure1 below. In line with the application of coaching, the conceptual framework identifies the leader as the central point, describing leader characteristics as "congruence" or "incongruence" by the culture of the organization. Just like previous fit studies, cases of similarity and dissimilarity can be characterized within the conceptual framework (Edwards \& Shipp, 2007). Similarity arise out of a high level of fit between the behaviour of the leader and culture on a specific characteristic, for instance, when a corporate leader has robust teamwork skills concurrently that the corporation is resilient on this characteristic (congruence high), or on the other hand, when both the corporate leader and corporation are weak relative to exercising teamwork well (congruence low). Then again, dissimilarity comes about when the corporate leader and corporation are unrelated in one of two ways. In particular, a corporate leader can have strong competences in teamwork simultaneously that the corporation is low on this characteristic (incongruence high), or with the other way round, the corporate leader could demonstrate weak teamwork skills while the corporation is high on teamwork (incongruence low). The four forms are not meant to reflect all likely distinctions, such as differences in the extent of leader-organizational culture congruence, but to a certain extent, to discover the fundamental dynamics so that consultant coaches can integrate this data to guide their approaches and support the design and provision of coaching. 


\begin{tabular}{|c|c|c|c|}
\hline \multirow{2}{*}{} & \multicolumn{3}{|c|}{ Parallel characteristics of business leader } \\
\cline { 2 - 4 } & & Low & High \\
\cline { 2 - 4 } & High & $\begin{array}{c}\text { Incongruence Low: } \\
\text { Leverage high culture } \\
\text { characteristics in leader } \\
\text { development and effectiveness }\end{array}$ & $\begin{array}{c}\text { Congruence High: } \\
\text { Build on high Leader and } \\
\text { cultural characteristics }\end{array}$ \\
\cline { 2 - 4 } & Low & $\begin{array}{c}\text { Congruence Low: } \\
\text { Train leader and organizational } \\
\text { culture; surmount the fact that } \\
\text { culture hinder leader }\end{array}$ & $\begin{array}{c}\text { Incongruence High: } \\
\text { Develop leader as negotiator } \\
\text { and agent for culture } \\
\text { transformation }\end{array}$ \\
\hline
\end{tabular}

Figure1. Framework on Leader and Organizational Culture Congruence

\subsection{Incongruence Lows}

The culture offers a special opportunity for a leader's growth and development when an ineffective or non-existent characteristic of the leader is in line with a parallel characteristic that is existing in the culture of the organization. The reason is that existing both behavioural norms and work practices possibly give a rich pool of experiences and motivations that encourages learning on-the-job. For instance, learning can take place rapidly through everyday business activities when it is likely to observe employees role-modelling the required capabilities. Similarly, there are likely to be several occasions to implement new behaviours acquired and receive more feedback.

Concerning the extent of cultural support that is available, prospects for the leader's advancement may be equally finely tuned. Cultural values and norms that are strongly held inside the company can be a factor of a stronger desire for how corporate leaders should perform, intensify the most important of executive behaviours and practices that are asymmetrical with the organizational culture, and increase the negative effects connected with behaving contrary to cultural values, norms and practices (Hanges, Dorfman, Shteynberg, \& Bates, 2006). In the same way, adaptation around profoundly rooted elements of the culture will aptly increase the leader's socialization and advancement within the company, while failure to assimilate could hinder one's vocational development.

On the basis of the above concerns, consultant coaches may want to prioritize leadership development on characteristics that match with this type of congruence, if the conclusion is that more of this characteristic is required from the leader. Because of intense expectations (push factors) as well as positive cultural support (pull factors) considerations, setting aggressive goals to concentrate on these characteristics may be suitable. Certainly, adjustments can be made to reflect the extent of disconnection between the leader and organizational culture. That is, the degree to which the leader's competences is weak or underdeveloped in relation to the organizational culture. For instance, a coach may desire to the assign the greatest priority to leader characteristics that are both significantly misaligned and inadequately developed with the culture. If in such extreme situations or more reasonable cases, the consultant coach can rely on the corporation as a supportive work environment for the leader's development. Based on this point of view, professional coaching can facilitate the integration of the leader with development opportunities that are underway, ask for supplementary feedback while on the job, persuade the leader to practice new skills, and look for mentors or counsellors within the organization, particularly corporate leaders who possess robust capabilities in critical areas. Additionally, executive coaching provides a safe haven to reflect on one's experiences, monitor the progress of the leader, and sustain accountability for future positive growth. A favourable and supportive environment provides emotional wellbeing for learning and human development (Avolio \& Hannah, 2008).

\subsection{Congruence Highs}

This perspective comes about when a leader's characteristic is compatible with a high degree of the parallel characteristic in the organizational culture. For competences that match with this type, the orientation of coaching logically changes towards a positive psychology standpoint of leadership, whereby the key objectives are to make better and realize the maximum potential of characteristics that the leader already may have had (Grant \& Spence, 2010). In line with a positive psychology standpoint, it is crucial for consultant coaches and executives to appreciate that the areas of strength also need special development strategies. For instance, there could be ways to sharpen and refine 


\section{Dr. Remy Nyukorong}

leadership skills so as to attain even elevated levels of personal effectiveness. For example, by assisting the leader to discover innovative learning and teaching prospects, including stretch assignments and acting as a mentor for other employees.

In a similar way, professional coaches need to become aware that by overstressing the areas suggested above, can give rise to overlooking or even intensifying comparative shortcomings that can weaken team functioning and effectiveness (Kaplan \& Kaiser, 2009). Otherwise stated, consultant coaches should take care that the characteristics are not uncritically developed at the cost of performance. It is also important to recognize that there are more organizational influences alongside culture that need to be accounted for in the whole process. In general, coaching must stimulate leaders to reconnoitre the highest levels of their capabilities, eschew unnecessary ceilings, as well as, be mindful of managing characteristics that leaders already demonstrate, so that these attributes or characteristics do not become superfluous or destructive due to overuse.

Another related factor with critical implications for executive coaching borders on how the leader applies culturally supported competencies to the benefit of the entire organization. As with people, corporations can always derive great benefits from further development of qualities, which may already be fully developed (Grant \& Spence, 2010). Certain attributes of the organizational culture may be clearly observable, commonly shared, and fully leveraged inside the corporation, in a way that cultural preservation is the most critical role that a corporate leader can engage in. In this situation, professional coaching can enable the leader to act in ways that endorse and sustain the culture for internal stakeholders and explain core cultural values and norms to the general public, including external stakeholders as well as new employees of the corporation. Certain elements of the culture may epitomize emerging characteristics that have not been embedded in the organization. Coaching is required to increase the awareness of leaders on these cultural properties and train leaders to promote these values and norms within the collective consciousness of the corporation, so that the values and norms can be fully leveraged and conform to the organizational strategy.

\subsection{Incongruence Highs}

This situation suggests a current leader quality which is deficient or inadequately developed within the culture. In such a situation, the leader ought to be particularly situated to influence the articulation and development of the cultural values and customs within the company, granted that this is appropriate within the given context. Nevertheless, this picture may also require the inherent capacity for a profound and more structural culture transformation within the corporation, increasing substantial complexity to the agentic leader role and the coaching approach necessary for the effective facilitation of the agentic leader role. Although the agentic leader view might seem the ideal condition for coaching business leaders or other leaders who naturally represent the key drivers of culture change for the entire corporation, the paper suggests its usability with line managers and even workmates who are co-responsible for the preservation, sustainability and shaping of the culture of the organization (Schneider, Smith, \& Fleenor, 1998; Chiaburu \& Harrison, 2008). Besides, the current paper envisages that the complexities explained below could run through in the same way throughout all organizational levels.

One point for early consideration has to do with the organization's preparedness and passion for culture change. The precise coaching approaches espoused will most likely differ substantially according to the organization's acceptance and understanding of the existing organizational culture, the amount of support and motivation for transformation, and whether there is a change program currently going on. For corporations or companies already implementing culture change initiatives, coaching can enable the leader to identify personal capabilities as an advocate or an agent in the continuing change process and explain the scope of engagement that would be required. Professional coaching can further help leaders as well as organizations to identify effective strategies for gaining support and developing key collaborations with interested parties involved in the change process, and subsequently, search for ways to be more effective as an agent of organizational change.

Alternatively, the expectations and goals of coaching could be fine-tuned, should there arise any conflict or general lack of understanding concerning the situation of the culture as well as its initiating cause. Based on several factors, including the role, credibility and experience the leader within the particular organization, the related risks of advocating for a culture change might be greater than the 
benefits. Otherwise stated, the consultant coach may speed up the leader's decision to postpone a vital agentic role a different time or pass it over to other members of the organization. Executive leaders who have a well-defined task and stake in the organization's culture, professional coaching need to be consistent with initial stages of culture change, encouraging the leader to initiate the process of repealing existing organizational cultural values and customs (Weick \& Quinn, 1999). Team building is a critical issue. Working individually as a culture change agent without first getting the support and cooperation of critical stakeholders is likely to dislocate the entire change initiative before it can gain impetus. Professional coaching has the ability to provide this momentum by assisting the leader to enter into strategic partnerships, as well as, deal with potential errors during the process.

Combining professional coaching with organizational improvement initiatives presents several practical challenges that deserve careful thought, although the current paper is of the opinion that the advantages to the organization and leader will rationalize the attendant costs in various ways. Most clearly, professional coaching may be required to obtain the commitment and support from a majority of stakeholders than is usually necessary in independently driven leader-development programmes. Also, widening the scope of professional coaching to target the leader's influence on organizational culture may involve the application of innovative methodologies and tools to monitor and supervise progress. For example, carrying out periodic cultural surveys will allow the identification of "hotspots" and "high-spots" for action. Finally, considering the complexity involved in culture change, an extended coaching schedule may be indispensable. On the whole, this may require a lot of flexibility in the coaching procedures that are employed, such as a mixture of several internal and external coaching activities.

\subsection{Congruence Lows}

Scoring low on a leader characteristic that also do not have strong cultural support could bring about specific challenges towards leader training and development. If that occurs, culture can serve either a passive or an active role in limiting the development of the leader. Developing or weak cultural values and customs can lead to a lack of clearness by producing varied or conflicting signals as regards the leadership actions that are treasured in the organization. Consequently, the leader may receive limited or insignificant support for learning and putting into practice new skills within the work environment, but lacking dedicated collaboration from other members, is at risk of complacency and engaging in behavioural practices with the passage of time. Other options can include more active types of resistance, for instance when the application of certain behaviours and leadership styles are in conflict with the organizational culture. For such situations, the leader is not likely to get sufficient improvement and development support in the organization. And if development and improvement do not take place through external opportunities, it may be hard for the leader to pass on recently acquired skills to the work setting (Orenstein, 2002; Tobias, 1996).

In order to avoid inertia and problems related to transfer, a critical first action for the consultant coach is to realize and appreciate the events surrounding inconsistent or low cultural patronage. Perhaps in many cases, one will expect that the absence of cultural endorsement for particular competences will initiate a challenge for the leader's development instead of an entirely barricade. The current paper also admits that carrying on with restraint could be less likely if organizational requirements assign high priority to the acquisition and development of new competences which are not supported by the organizational culture. The solution then for professional coaching might be to comprehend the specific challenges posed by the organizational culture, increase the awareness of leaders to these challenges, and make concrete adaptations to the development schemes correspondingly. For instance, when cultural endorsement is extremely low, the coaching plan could concentrate on identifying and linking the leader with outside developmental prospects such as workshops, conferences and off-site training. However, when cultural backing gets to a more moderate heights, it may otherwise be feasible to mobilize internal pockets of sponsorship (patronage) inside the company, such as important action groups that are passionately involved in bringing about culture change. In each case, it may be necessary for professional coaches and leaders to adapt individual expectations and operational schedule to have capacity for a likely lengthier and more incremental growth path, and the intensified possibility of frustrations and setbacks. 


\section{METHODOLOGICAL IMPERATIVES}

Having extensively described the conceptual framework, a series of methodological imperatives should also be given some attention. Understanding and appreciating that an exhaustive treatment of all match-measurement cases is outside the purview of the current paper (Edwards \&Parry, 1993; Edwards \& Shipp, 2007; Kristof-Brown et al., 2005). In this unit, the author describes the precise prerequisites and considerations for applying the FLOCC as a useful and down-to-earth solution for executive coaching.

The methodological preconditions for the proposed framework are threefold. First of all, the paper proposes that knowing and understanding how to apply fit data in real life necessitates an evaluative assessment as regards the meaning of characteristics or qualities, based on the level of expression. Consultant coaches and business executives will need to decide whether smaller amounts or more of the evaluative characteristics are relevant within the given circumstances to clarify the objective of development initiatives. Assuming descriptive tools are applied, consultant coaches may be required to stimulate a systematic sense-making process to extrapolate the effectiveness or ineffectiveness of measurement scores. Even though prescriptive devices may be effective incidentally, more contextualization of the outcomes is still required to make sure that there is a consistent basis for accepting and taking action on the results.

Secondly, it is important to use parallel characteristics or attributes as a methodological requirement. As mentioned earlier on, parallel characteristics are needed to offer the familiar, everyday language and foundation for evaluating a leader and the organizational culture; for instance, the leader teamwork behaviours, as well as, the corresponding norms and set of values proximate to teamwork in the organization.

The third methodological requirement is the application of commensurate measures (Kristof, 1996). Commensurate measures collect the data in a way that enables direct comparison of both the leader and organizational. This entails utilizing tools and analytic techniques that generate scores to be decoded and construed with a shared meaning (Caplan, 1987; Edwards, 1991; Kristof, 1996). Supposing the fundamental preconditions can be obtained, the implementation of the conceptual framework is not linked to a specific methodology or set of measurement tools.

\section{DisCuSSION}

Even though there is increasing recognition of the universal significance of leader-organizational culture alignment, the author is not aware of any research exploring the congruence concept in the field of coaching and leader development (Burns et al., 2013). Thus, this is an awkward gap for practitioners, who carry out leader-development interventions surrounding the cultural setting of organizations and whose customers' success relies greatly on effective leader and organizational culture dynamics (Hartnell \& Walumbwa, 2011; Schein, 1983, 1985). To deal with this constraint, the current paper initiated a conceptual model for coaching focused on various forms of leaderorganizational culture congruence and reviewed applicable methodologies for its implementation. The purpose of the model is to aid the construction of a more precise the interaction between leader and organizational cultural characteristics, and to relate these dynamics to a number of unique strategies and approaches for coaching. Though this paper is of the view that there is robust potential in the FLOCC as a practical model, it is imperative to identify the challenges that consultant coaches could face when trying to implement this model in executive coaching, in addition to the set of corresponding shortcomings.

\section{Challenges}

The biggest challenge researching into leader-organizational culture alignment has to do with connecting the coaching engagement to wider organizational development considerations and requirements. Even though this challenge can be an overwhelming experience, there is increasing acknowledgement that the benefits of aligning leadership and organizational development are greater than the attendant costs (Barriere, Anson, Ording, \& Rogers, 2002; Guidroz et al., 2010; Hostetler, 2007). Similarly, this paper is of the view that the FLOCC will be highly effective as an executive coaching approach when close connections can be made with all relevant stakeholders and goals of continuous organizational development; and less effective when executive coaching takes place out of context or as an entirely personal development intervention (Feldman \& Lankau, 2005; Kilburg, 1996; Peterson, 2009; Saporito, 1996). 
Designing these organizational and individual synergies demands that consultant coaches not barely possess a distinct combination of skills set and capabilities, but also that consultant coaches engage with a bigger number of both internal and external stakeholders than is customary of coaching arrangements. The significance of these collaborations is obvious at several phases of the coaching process. Preceding implementing the evaluative assessments, the input of key stakeholders can be valuable towards understanding the existing organizational development goals, the major concerns and challenges bounding on the business setting, and when delineating the methodology and scope of the leader and organizational culture evaluations. If possible, the same key stakeholders should endeavour to support the appraisal process and be a bigger part in the interpretation of the culture measurement outcomes. Allowing for the participation of others in the sense-making process can make certain that organization cultural lows and highs are fully understood with respect to critical operational and business considerations. These shared insights can help to highlight the orientation and type of the leader's follow-up activities, mobilize support for leader development, and even build the impetus for change in particular attributes of organizational culture. Ultimately, constant and timely feedback from principal stakeholders within the company is an essential part of supervising development progress over time.

A difficult specific challenge borders on the addition of the culture evaluative assessment to the more mainstream series of interventions and set of tools that consultant coaches utilize with leaders. Although a number of professional coaches may not have real life or first-hand experience in carrying out and deducing inferring from organizational assessments, the author is of the view that the tougher difficulty will involve getting the support of organizational members, which is required to cope with a data gathering process at scale. Given this challenge, there are two specific cases that set a promising platform for the implementation of the proposed framework: when the coaching engagement is linked specifically to organizational culture change process as has been described in this paper, or as an alternative, when executive coaching is performed as part of a global, across-the-board leadership development agenda with several corporate leaders. Again, this paper recognizes that it might be more cumbersome to garner support in the instance of stand-alone coaching interventions.

\section{Conclusion, Limitations and Recommendations for Practice and Future RESEARCH}

Besides surmounting these practical challenges, there are a number of extra structural constraints of the proposed approach that stand calling to attention. One weak point follows from the fact that the FLOCC is an innovative conceptual model. Therefore, this current study is unable to point at empirical, first-hand research papers that have assessed the proposed framework compared with other coaching approaches, though this undoubtedly embodies a notable future direction. Regrettably, a comparable observation pertains on the whole within the executive coaching purview, as the effects of diverse coaching methodologies are usually not well understood (Feldman \& Lankau, 2005).

In the same vein, the explicit effects of the four kinds of leader-organizational culture congruence on different development, as well as, effectiveness results are mostly unverified at this point in time (Burns et al., 2013). Besides examining predictive relationships, research in the future should also endeavour to unravel the set of characteristics within a multiple-element perspective that emerge most significant to consider, and hypothetical contingency considerations. Instead of making an effort to categorize all of these distinctions and interpret them into prescriptive measures now, the purpose of this study was to elaborate a practicable set of speculative factors, which reflect the fundamental differences of leader-organizational culture congruence and which could serve as a valuable model within executive coaching. Hence, as with this contextualized viewpoint of the proposed framework, the paper recommends that consultant coaches apply the four meta-perspectives as a variable beginning and custom-build their specific methods correspondingly. Finally, the paper forecasts that the results of future research will help to improve the conceptual model in its implementation. 


\section{REFERENCES}

Allworth, E., \& Griffin, B. (2005). The application of psychological assessment to executive coaching. In M. Cavanagh, A. Grant, T. Kemp (Eds.), Evidence-based coaching: Vol. 1. Theory, research and practice from the behavioural sciences (pp. 97-110). Bowen Hills, QLD, Australia: Australian Academic Press.

Ashkanasy, N. M., Broadfoot, L. E., \& Falkus, S. A. (2000). Questionnaire measures of organizational culture. In N. Ashkanasy, C. Wilderom, \& M. Peterson (Ed.), Handbook of Organizational Culture and Climate (pp. 131-145). Thousand Oaks, CA: Sage.

Avolio, B. J., \& Hannah, S. T. (2008). Developmental readiness: Accelerating leader development. Consulting Psychology Journal: Practice and Research, 60, 331. doi:10.1037/10659293.60.4.331

Atwater, L. E., \& Yammarino, F. J. (1997). Self-other rating agreement. In G. R. Ferris (Ed.), Research in personnel and human resources management (Vol. 15, pp. 121-174). Greenwich, CT: JAI Press.

Barriere, M. T., Anson, B. R., Ording, R. S., \& Rogers, E. (2002). Culture transformation in a healthcare organization: A process for building adaptive capabilities through leadership development. Consulting Psychology Journal: Practice and Research, 54, 116-130. doi:10.1037/1061-4087.54.2.116

Bennis, W., \& Nanus, B. (1985). Leaders. New York, NY: Harper \& Row.

Bono, J. E., Purvanova, R. K., Towler, A. J., \& Peterson, D. B. (2009). A survey of executive coaching practices. Personnel Psychology, 62, 361-404. doi:10.1111/j.1744-6570.2009.01142.x

Bourne, A. (2008). Using psychometrics in coaching. In S. Palmer, \& A. Whybrow (Eds.), Handbook of coaching psychology: A guide for practitioners (pp. 385-403). New York, NY: Routledge/Taylor \& Francis.

Bracken, D. W., \& Rose, D. S. (2011). When does 360-degree feedback create behavior change? And how would we know it when it does? Journal of Business and Psychology, 26, 183-192. doi:10.1007/s10869-0119218-5

Burns, G. N., Kotrba, L. M., \& Denison, D. R. (2013).Leader-culture fit: Aligning leadership and corporate culture. In H. S. Leonard, R. Lewis, A. M. Freedman, \& J. Passmore (Eds.), The WileyBlackwell handbook of the psychology of leadership, change and organizational development (pp. 113-128). Hoboken, NJ: Wiley. doi:10.1002/9781118326404.ch6

Caldwell, D., \& O'Reilly, C. (1990). Measuring person-job fit using a profile comparison process. Journal of Applied Psychology, 75, 648-657. doi:10.1037/0021-9010.75.6.648

Caplan, R. D. (1987). Person-environment fit theory and organizations: Commensurate dimensions, time perspectives, and mechanisms. Journal of Vocational Behavior, 31, 248-267. doi: $10.1016 / 00018791(87) 90042-X$

Caplan, R. D., \& Van Harrison, R. (1993). Person-environment fit theory: Some history, recent developments, and future directions. Journal of Social Issues, 49, 253-275. doi:10.1111/j.15404560.1993.tb01192.x

Carter, N. T., Kotrba, L. M., Diab, D. L., Lin, B. C., Pui, S. Y., Lake, C. J.,...Chao, A. (2012). A comparison of a subjective and statistical method for establishing score comparability in an organizational culture survey. Journal of Business and Psychology, 27, 451-466. doi: 10.1007/s10869-011-9254-1

Chatman, J. A. (1989). Improving interactional organizational research: A model of personorganization fit. The Academy of Management Review, 14, 333-349. doi: 10.2307/258171

Chatman, J. A., \& Cha, S. E. (2003). Leading by leveraging culture. California Management Review, 45, 20-34. doi: 10.2307/41166186

Chiaburu, D. S., \& Harrison, D. A. (2008). Do peers make the place? Conceptual synthesis and metaanalysis of co-worker effects on perceptions, attitudes, OCBs, and performance. Journal of Applied Psychology, 93, 1082.. doi:10.1037/0021-9010.93.5.1082

Church, A. H., \& Waclawski, J. (1998). Designing and using organizational surveys: A seven step process. San Francisco, CA: Jossey-Bass. 
Cooke, R. A., \& Rousseau, D. M. (1988). Behavioural norms and expectations: A quantitative approach to the assessment of organizational culture. Group \& Organizational Management, 13, 245-273. doi: 10.1177/ 105960118801300302

Cooke, R. A., \& Szumal, J. L. (1993). Measuring normative beliefs and shared behavioural expectations in organizations: The reliability and validity of the organizational culture inventory. Psychological Reports, 72, 1299-1330. doi:10.2466/pr0.1993.72.3c.1299

Coultas, C. W., Bedwell, W. L., Burke, C. S., \& Salas, E. (2011). Values sensitive coaching: The DELTA approach to coaching culturally diverse executives. Consulting Psychology Journal: Practice and Research, 63, 149-161. doi: 10.1037/a0025603

Coutu, D., \& Kauffman, C. (2009). What can coaches do for you? Harvard Business Review, January, 90-92.

Dalessio, A. T. (1998). Using multisource feedback for employee development and personnel decisions. In J. W. Smither (Ed.), Performance appraisal: State-of-the-art in practice (pp. 278330). San Francisco, CA: Jossey-Bass.

Day, D. V. (2000). Leadership development: A review in context. The Leadership Quarterly, 11, 581613. doi: 10.1016/S1048-9843(00)00061-8

Deal, T. E., \& Kennedy, A. A. (1982). Corporate cultures. Reading, MA: Addison Wesley.

De Cooman, R., De Gieter, S., Pepermans, R., Hermans, S., Du Bois, C., Caers, R., \& Jegers, M. (2009).

Person-organization fit: Testing socialization and attraction-selection-attrition hypotheses. Journal of Vocational Behavior, 74, 102-107. doi:10.1016/j.jvb.2008.10.010

Denison Consulting (2008). Change over time: New Hampshire Electric Cooperative. Unpublished white paper. [Online]Available: http://www.denisonconsulting.com/resource-library/changeover-time-new-hampshireelectric-cooperative (April 29, 2016).

Denison, D. R. (1984). Bringing corporate culture to the bottom line. Organizational Dynamics, 13, 5-22. doi: 10.1016/0090-2616(84)90015-9

Denison, D. R. (1996). What is the difference between organizational culture and organizational climate? A native's point of view on a decade of paradigm wars. The Academy of Management Review, 21, 619-654. doi: 10.2307/258997

Denison, D. R., Hooijberg, R., \& Quinn, R. E. (1995). Paradox and performance: Toward a theory of behavioural complexity in managerial leadership. Organization Science, 6, 524-540. doi:10.1287/orsc.6.5.524

Denison, D. R., Kotrba, L. K., \& Castaño, N. (2012). A cross-cultural perspective on leadership assessment: Comparing 360-degree feedback results from around the world. In W. H. Mobley, Y. Wang, \& M. Li (Eds.), Advances in global leadership (Vol. 7, pp. 205-228). Bingley, UK: Emerald Group. doi: 10.1108/S15351203 (2012)0000007013

Denison, D. R., \& Mishra, A. (1995). Toward a theory of organizational culture and effectiveness. Organization Science, 6, 204-223. doi:10.1287/orsc.6.2.204

Denison, D. R., \& Neale, W. S. (1996a). Denison organizational culture survey. Ann Arbor, MI: Aviat.

Denison, D. R., \& Neale, W. S. (1996b). The Denison leadership development survey. Ann Arbor, MI: Aviat.

Denison, D. R., Nieminen, L. R., \& Kotrba, L. (in press). Diagnosing organizational cultures: A conceptual and empirical review of culture effectiveness surveys. European Journal of Work and Organizational Psychology. Advance online publication. doi:10.1080/1359432X.2012.713173

Edwards, J. R. (1991). Person-job fit: A conceptual integration, literature review, and methodological critique. In C. L. Cooper \& I. T. Robertson (Eds.), International Review of Industrial and Organizational Psychology (vol. 6, pp. 283-357). New York: Wiley.

Edwards, J. R., \& Parry, M. E. (1993). On the use of polynomial regression equations as an alternative to difference scores in organizational research. Academy of Management Journal, 36, 15771613. doi: $10.2307 / 256822$ 
Edwards, J. R., \& Shipp, A. J. (2007). The relationship between person-environment fit and outcomes: An integrative theoretical framework. In C. Ostroff, \& T. A. Judge (Eds.), Perspectives on organizational fit (pp. 209-258). New York, NY: Erlbaum.

Feldman, D. C. (2001). Career coaching: What HR professionals and managers need to know. Human Resource Planning, 24, 26-35.

Feldman, D. C., \& Lankau, M. J. (2005). Executive coaching: A review and agenda for future research. Journal of Management, 31, 829-848. doi: 10.1177/0149206305279599

Fleenor, J. W., Smither, J. W., Atwater, L. E., Braddy, P. W., \& Sturm, R. E. (2010). Self-other rating agreement in leadership: A review. The Leadership Quarterly, 21, 1005-1034. doi:10.1016 /j.leaqua.2010.10.006

Gentry, W. A., \& Eckert, R. H. (2012). Integrating implicit leadership theories and fit into the development of global leaders: A 360-degree approach. Industrial and Organizational Psychology: Perspectives on Science and Practice, 5, 224-227. doi:10.1111/j.17549434.2012.01434.x

Gilbert, K., \& Rosinski, P. (2008). Accessing cultural orientations: The online cultural orientations framework assessment as a tool for coaching. Coaching: An International Journal of Theory, Research and Practice, 1, 81-92. doi: 10.1080/17521880701878018

Gillespie, M., Denison, D., Haaland, S., Smerek, R., \& Neale, W. (2008). Linking organizational culture and customer satisfaction: Results from two companies in different industries. European Journal of Work and Organizational Psychology, 17, 112-132. doi: $10.1080 / 13594320701560820$

Goodstone, M. S., \& Diamante, T. (1998). Organizational use of therapeutic change: Strengthening multisource feedback systems through interdisciplinary coaching. Consulting Psychology Journal: Practice and Research, 50, 152-163. doi:10.1037/1061-4087.50.3.152

Grant, A. M., \& Spence, G. B. (2010). Using coaching and positive psychology to promote a flourishing workforce: A model of goal-striving and mental health. In P. A. Linley, S. Harrington, \& N. Garcea (Eds.), Oxford handbook of positive psychology and work (pp. 175188). New York, NY: Oxford University Press.

Guidroz, A. M., Luce, K. W., \& Denison, D. R. (2010). Integrated change: Creating synergy between leader and organizational development. Industrial and Commercial Training, 42, 151-155. doi: 10.1108/00197851011038141

Hanges, P., Dorfman, P., Shteynberg, G., \& Bates, A. L. (2006). Culture and leadership: A connectionist information processing model. Advances in Global Leadership, 4, 7-37. doi: 10.1016/S15351203 (06)04004-4

Harrison, D. A. (2007). Pitching fits in applied psychological research: Making fit methods fit theory. In C. Ostroff, \& T. A. Judge (Eds.), Perspectives on organizational fit (pp. 389-416). New York, NY: Erlbaum.

Hartnell, C. A., Ou, A. Y., \& Kinicki, A. (2011). Organizational culture and organizational effectiveness: A meta-analytic investigation of the competing values framework's theoretical suppositions. Journal of Applied Psychology, 96, 677-694. doi: 10.1037/a0021987

Hartnell, C. A., \& Walumbwa, F. O. (2011). Transformational leadership and organizational culture: Toward integrating a multilevel framework. In N. Ashkanasy, C. Wilderom, \& M. Peterson (Eds.), The handbook of organizational culture and climate (2nd ed., pp. 225-248). Los Angeles, CA: Sage. doi: 10.4135/ 9781483307961.n13

Hazucha, J. F., Hezlett, S. A., \& Schneider, R. J. (1993). The impact of 360-degree feedback on management skills development. Human Resource Management, 32(2-3), 325-351. doi:10.1002/hrm.3930320210

Hedge, J. W., \& Borman, W. C. (1995). Changing conceptions and practices in performance appraisal. In A. Howard (Ed.), Frontiers of industrial and organizational psychology: The changing nature of work. Sacramento, CA: Jossey-Bass.

Hofstede, G. (1980). Culture's consequences: International differences in work-related values. Beverly Hills, CA: Sage. 
Hostetler, E. (2007). Safety at the centre: A model that accelerates learning. Organization Development Journal, 25, 63-66.

Hyman, D. J., Pavlik, V. N., Taylor, W. C., Goodrick, G. K., \& Moye, L. (2007). Simultaneous vs. sequential counselling for multiple behavior change. Archives of Internal Medicine, 167, 1152. doi: 10.1001/ archinte.167.11.1152

Jansen, K. J., \& Kristof-Brown, A. (2006). Towards a multidimensional theory of personenvironment fit. Journal of Managerial Issues, 18, 193-212.

Javidan, M., House, R. J., \& Dorfman, P. W. (2004). A nontechnical summary of GLOBE findings. In R. J. House, P. J. Hanges, M. Javidan, P. W. Dorfman, \& V. Gupta (Eds.), Leadership, culture, and organizations: The GLOBE study of 62 societies (pp. 122-125). Thousand Oaks, CA: Sage.

Johns, G. (2006). The essential impact of context on organizational behavior. The Academy of Management Review, 31, 386-408. doi:10.5465/AMR.2006.20208687

Kaiser, R., \& Overfield, D. (2011). Strengths, strengths overused, and lopsided leadership. Consulting Psychology Journal: Practice and Research, 63, 89-109. doi: 10.1037/a0024470

Kaplan, R. E., \& Kaiser, R. B. (2009). Stop overdoing your strengths. Harvard Business Review, 87, $100-103$.

Kauffman, C., \& Coutu, D. (2009). The realities of executive coaching. Harvard Business Review Research Report, January, 1-25.

Kilburg, R. R. (1996). Toward a conceptual understanding and definition of executive coaching. Consulting Psychology Journal: Practice and Research, 48, 134-144. doi:10.1037/10614087.48.2.134

Klimoski, R. (2012). Commentary: When it comes to leadership, context matters. In M. Rumsey (Ed.), Oxford handbook on leadership (Online publication). Oxford, UK: Oxford University Press. doi:10.1093/oxfordhb/ 9780195398793.013.0016

Kotrba, L. M., Gillespie, M. A., Schmidt, A. M., Smerek, R. E., Ritchie, S. A., \& Denison, D. R. (2012). Do consistent corporate cultures have better business performance? Exploring the interaction effects. Human Relations, 65, 241-262. doi: 10.1177/0018726711426352

Kotter, J., \& Heskett, J. (1992). Corporate culture and performance. New York, NY: Free Press.

Kristof, A. L. (1996). Person-organization fit: An integrative review of its conceptualizations, measurement, and implications. Personnel Psychology, 49, 1-49. doi:10.1111/j.17446570. 1996.tb01790.x

Kristof-Brown, A., \& Guay, R. P. (2011). Person-environment fit. In S. Zedeck (Ed.), APA handbook of industrial and organizational psychology: Vol. 3. Maintaining, expanding, and contracting the organization (pp. 3-50). Washington, DC: American Psychological Association. doi: 10.1037/12171-001

Kristof-Brown, A. L., Zimmerman, R. D., \& Johnson, E. C. (2005). Consequences of individuals' fit at work: A meta-analysis of person-job, person-organization, person-group, and personsupervisor fit. Personnel Psychology, 58, 281-342. doi:10.1111/j.1744-6570.2005.00672.x

Lance, C. E., Hoffman, B. J., Gentry, W. A., \& Baranik, L. E. (2008). Rater source factors represent important subcomponents of the criterion construct space, not rater bias. Human Resource Management Review, 18, 223-232. doi:10.1016/j.hrmr.2008.03.002

Lebreton, J. M., Burgess, J. R. D., Kaiser, R. B., Atchley, E. K., \& James, L. R. (2003). The restriction of variance hypothesis and interrater reliability and agreement: Are ratings from multiple sources really dissimilar? Organizational Research Methods, 6, 80-128. doi: $10.1177 / 1094428102239427$

Luthans, F., \&Peterson, S.J. (2003).360degree feedback with systematic coaching: Empirical analysis suggests a winning combination. Human Resource Management, 42, 243-256. doi:10.1002/ hrm. 10083

Meglino, B. M., \& Ravlin, E. C. (1998). Individual values in organizations: Concepts, controversies, and research. Journal of Management, 24, 351-389. doi.10.1016/S0149-2063 (99)80065-8

Mowday, R. T., \& Sutton, R. I. (1993). Organizational behavior: Linking individuals and groups to organizational contexts. Annual Review of Psychology, 44, 195-229. doi:10.1146/annurev.ps. 44.020193.001211 
Nieminen, L., Biermeier-Hanson, B., \& Denison, D. (2013). Aligning leadership and organizational culture: The leader-culture fit framework for coaching organizational leaders. Consulting Psychology: Practice and Research, 65 (3), 177-198. Doi: 10.1037/a0034385.

Nowack, K., \& Mashihi, S. (2012). Evidence-based answers to 15 questions about leveraging 360degree feedback. Consulting Psychology Journal: Practice and Research, 64, 157-182. doi: 10.1037/a0030011

O'Reilly, C. A., Chatman, J., \& Caldwell, D. F. (1991). People and organizational culture: A profile comparison approach to assessing person-organization fit. Academy of Management Journal, 34, 487-516. doi:10.2307/ 256404

Orenstein, R. L. (2002). Executive coaching: It's not just about the executive. Journal of Applied Behavioural Science, 38, 355-374. doi: 10.1177/0021886302038003006

Peltier, B. (2001). The psychology of executive coaching: Theory and application. Ann Arbor, MI: Sheridan Books. Peters, T. J., \& Waterman, R. H. (1982). In search of excellence: Lessons from America's best run companies. New York, NY: Harper \& Row.

Peterson, D. B. (2009). Coaching and performance management: How can organizations get the greatest value? In J. W. Smither, \& M. London (Eds.), Performance management: Putting research into practice (pp. 115-156). San Francisco, CA: Jossey-Bass.

Porter, L. W., \& McLaughlin, G. B. (2006). Leadership and the organizational context: Like the weather? The Leadership Quarterly, 17, 559-576. doi:10.1016/j.leaqua.2006.10.002

Rogelberg, S.G., Church, A.H., Waclawski, J., \&Stanton, J.M. (2002).Organizational survey research. In S.G. Rogelberg (Ed.), Handbook of research methods in industrial organizational psychology (pp. 141-160). Malden, MA: Blackwell.

Rokeach, M., \& Ball-Rokeach, S. J. (1989). Stability and change in American values, 1969-1981. American Psychologist, 44, 775-784. doi:10.1037/0003-066X.44.5.775

Rosinski, P. (2003). Coaching across cultures: New tools for leveraging national, corporate and professional differences. London, UK: Nicholas Brealey.

Rothaizer, J. M., \& Hill, S. L. (2010). What is an adequate knowledge base for executive coaching? International Journal of Coaching in Organizations, 29, 40-58.

Sackmann, S. A. (2011). Culture and performance. In N. Ashkanasy, C. Wilderom, \& M. Peterson (Eds.), The handbook of organizational culture and climate (2nd ed., pp. 188-224). Thousand Oaks, CA: Sage. doi:10.4135/9781483307961.n12

Saporito, T. J. (1996). Business-linked executive development: Coaching senior executives. Consulting Psychology Journal: Practice and Research, 48, 96-103. doi:10.1037/10614087.48.2.96

Schein, E. (1983). The role of the founder in creating organizational culture. Organizational Dynamics, 12, 13-28. doi: 10.1016/0090-2616(83)90023-2

Schein, E. (1985). Organizational culture and leadership. San Francisco, CA: Jossey-Bass.

Schneider, B., Smith, D. B., Taylor, S., \& Fleenor, J. (1998). Personality and organizations: A test of the homogeneity of personality hypothesis. Journal of Applied Psychology, 83, 462-470. doi:10.1037/00219010.83.3.462

Schwab, D. P., Heneman, H. G., DeCotiis, III, T. A. (1975). Behaviourally anchored ratings scales: A review of the literature. Personnel Psychology, 28, 549-562. doi:10.1111/j.1744-6570.1975. tb01392.x

Seifert, C. F., Yukl, G., \& McDonald, R. A. (2003). Effects of multisource feedback and a feedback facilitator on the influence behavior of managers toward subordinates. Journal of Applied Psychology, 88, 561. doi:10.1037/0021-9010.88.3.561

Smither, J. W., London, M. L., Flautt, R., Vargas, Y., \& Kucine, I. (2003). Can working with an executive coach improve multisource feedback ratings over time? A quasi-experimental study. Personnel Psychology, 56, 23-44. doi:10.1111/j.1744-6570.2003.tb00142.x

Tobias, L. L. (1996). Coaching executives. Consulting Psychology Journal: Practice and Research, 48, 87-95. doi:10.1037/1061-4087.48.2.87

Tobias, L. L. (2004). The thriving person and the thriving organization: Parallels and linkages. Consulting Psychology Journal: Practice and Research, 56, 3-9. doi:10.1037/1061-4087.56.1.3 
Trice, H., \& Beyer, J. (1991). Cultural leadership in organizations. Organization Science, 2, 149-169. doi: $10.1287 /$ orsc.2.2.149

Verquer, M. L., Beehr, T. A., \& Wagner, S. H. (2003). A meta-analysis of relations between personorganization fit and work attitudes. Journal of Vocational Behaviour, 63, 473-489. doi: 10.1016/S00018791 (02)00036-2

Weick, K. E., \& Quinn, R. E. (1999). Organizational change and development. Annual Review of Psychology, 50, 361-386. doi:10.1146/annurev.psych.50.1.361

Werbel, J. D., \& Gilliland, S. W. (1999). Person-environment fit in the selection process. Research in Personnel and Human Resources Management, 17, 209-243.

Wheeler, A. R., Gallagher, V. C., Brouer, R. L., \& Sablynski, C. J. (2007). When person-organization (mis)fit and (dis)satisfaction lead to turnover: The moderating role of perceived job mobility. Journal of Managerial Psychology, 22, 203-219. doi: 10.1108/02683940710726447

Yammarino, F. J., \& Atwater, L. E. (1993). Understanding self-perception accuracy: Implications for human resource management. Human Resource Management, 32, 231-247. doi:10.1002/ hrm.3930320204

Yukl, G., Fu, P. P., \& McDonald, R. (2003). Cross-cultural differences in perceived effectiveness of influence tactics for initiating or resting change. Applied Psychology: An International Review, 52, 68-82. doi: 10.1111/1464-0597.00124

Zickar, M., Barger, P., Guidroz, A., \& Yankelevich, M. (2007, March). White paper on norms: Prepared for Denison Consulting. Unpublished technical report. Bowling Green State University, Bowling Green, OH. [Online] Available: http://former.denisonconsulting.com/Libraries/ Resources/Zicker-2007-Norms.sflb.ashx (April 29, 2016)

\section{AUTHOR's BIOGRAPHY}

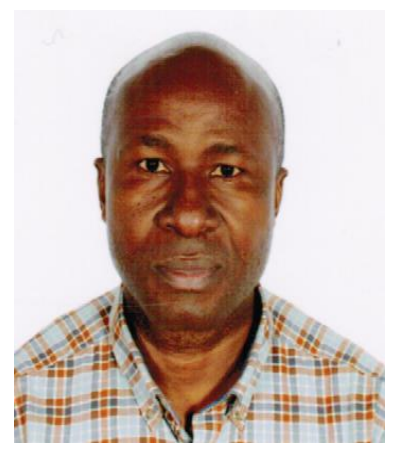

Dr. Remy Nyukorong, is General Treasurer of Stichting Kongregatie F.I.C., headquartered in the Netherlands. He is, at the same time, the Executive Director of Management Partners (GH), a professional management consulting firm in Ghana, which focuses on providing strategic, substantial, and pragmatic advisory services to public and private organizations and businesses to produce positive change and increase organizational effectiveness, by identifying issues and problems, and recommending ways to improve operations. He holds a Doctorate of Business Administration from Swiss Management Center University, (Switzerland), an MBA (Accounting \& Finance) from Maastricht School of Management (The Netherlands), and a BSc. (Hons.) degree in Education from St. Mary's University of Minnesota, USA (Nairobi campus, Kenya). He was a lecturer for several years at the Wa Polytechnic Business School in the Upper West Region of Ghana. His research interests are in the areas of leadership, organizational behavior, innovation \& entrepreneurship, marketing, finance and investment management.

gen.bursar@brothers-fic.org 